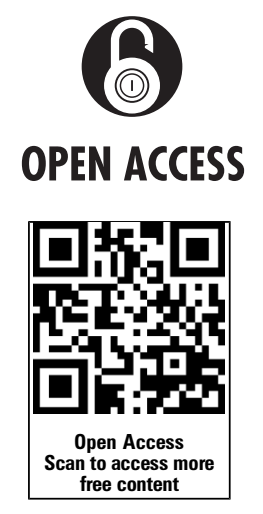

Handling editor Tore K Kvien

- Additional material is published online only. To view please visit the journal online (http://dx.doi.org/10.1136/ annrheumdis-2014-205698)

${ }^{1}$ Rheumatology Unit, Department of Medicine, Karolinska Institutet, Stockholm, Sweden ${ }^{2}$ Department of Rheumatology and Department of Clinical and Experimental Medicine, Linköping University, Linköping, Sweden

${ }^{3}$ Section of Rheumatology, Department of Medicine, Helsingborg's lasarett, Helsingborg, Sweden ${ }^{4}$ Section of Rheumatology, Department of Clinical Sciences, Skåne University Hospital, Lund, Sweden 5 Department of Learning, Informatics and Medical Education, Karolinska Institutet, Stockholm, Sweden ${ }^{6}$ Department of Orthopedics, Clinical Sciences Lund, Lund University, Lund, Sweden ${ }^{7}$ Unit for Clinical Therapy Research, Inflammatory Diseases, Karolinska Institutet, Stockholm, Sweden

\section{Correspondence to} Dr Alf Kastbom, Department of Rheumatology, IKE, Pathology building, floor 10, Linköping University Hospital, Linköping SE 581 85, Sweden; alf.kastbom@liu.se

Received 8 April 2014 Revised 31 October 2014 Accepted 7 November 2014 Published Online First 30 December 2014

\section{CrossMark}

To cite: Kastbom A,

Forslind K, Ernestam S, et al. Ann Rheum Dis

2016;75:356-361.

\title{
Changes in the anticitrullinated peptide antibody response in relation to therapeutic outcome in early rheumatoid arthritis: results from the SWEFOT trial
}

\author{
Alf Kastbom ${ }_{1}^{1,2}$ Kristina Forslind, ${ }^{3,4}$ Sofia Ernestam ${ }_{1}^{5}$ Pierre Geborek, ${ }^{4}$ \\ Johan A Karlsson, ${ }^{4}$ Ingemar F Petersson, ${ }^{6}$ Saedis Saevarsdottir, ${ }^{1}$ Lars Klareskog, ${ }^{1}$ \\ Ronald F van Vollenhoven, ${ }^{7}$ Karin Lundberg ${ }^{1}$
}

\section{ABSTRACT}

Objective To determine the relationship between changes in antibody levels towards citrullinated peptides derived from different candidate autoantigens and therapeutic outcome in early rheumatoid arthritis (RA). Methods Baseline and 3-month serum samples from 316 patients with early RA enrolled in the Swedish Farmacotherapy (SWEFOT) trial were analysed for antibodies against cyclic citrullinated peptides (CCP) and citrullinated peptides derived from vimentin (cVim), fibrinogen (cFib) and $\alpha$-enolase (CEP-1). At 3-month follow-up, methotrexate monotherapy-inadequate responders were randomised to add-on therapy with sulfasalazine and hydroxychloroquine or infliximab. In these patients, anticitrullinated peptide antibodies (ACPA) were also assessed at 12 and 24 months. The proportion of antibody-positive patients and relative changes in antibody levels were compared across ACPA specificities and related to therapeutic response and radiographic progression.

Results During the 2-year follow-up, the proportion of patients testing positive declined significantly regarding antibodies to CVim, cFib and CEP-1, while anti-CCP antibody occurrence remained stable over time. Turning anti-cVim antibody negative was most common, and anticVim antibody seroreversion during the first three months associated with significantly less 2-year radiographic progression compared with patients who remained positive. Median antibody levels of all tested ACPAs declined uniformly during initial methotrexate therapy and following response to add-on therapy, with no significant relation to treatment regimen or radiographic progression. Conclusions The influence of early antirheumatic therapy on ACPA seroreversions was markedly different across specificities, and early disappearance of anti-cVim antibodies associated with better radiological outcome. Thus, these data suggest that the disappearance of particular ACPA reactivities may be beneficial in early RA. Trial registration number $\mathrm{WHO}$ database at the Karolinska institute: CT20080004; and clinicaltrials.gov: NCT00764725.

\section{INTRODUCTION}

The discovery of autoantibodies recognising citrullinated proteins (ACPA) and the development of serological tests for their detection (most notably the cyclic citrullinated peptide (CCP) ELISA tests) have improved the ability to diagnose rheumatoid arthritis (RA) at an early stage and to identify patients at increased risk of a severe disease course. ${ }^{1}$ These clinically very useful tests do not, however, formally address the question of which specific citrullinated autoantigens are targeted. ${ }^{2}$ More recently, it has been demonstrated by several groups that antibodies towards immunodominant citrullinated epitopes of different candidate autoantigens can be detected by assays using citrullinated peptides derived from these different autoantigens, and that such antibodies have only a limited cross-reactivity with each other ${ }^{3}{ }^{4}$ and are subject to different genetic regulations. ${ }^{5}{ }^{6}$ It has also been demonstrated that antibodies to different citrullinated peptides emerge at different stages and with different dynamics prior to the clinical onset of RA. ${ }^{78}$

The increased knowledge concerning ACPAs has encouraged a number of studies addressing changes in ACPA levels in relation to therapeutic response (reviewed by Modi et al). ${ }^{9}$ This topic is relevant not only because of direct clinical applications but because it may also provide indirect evidence for the pathogenicity of different ACPAs. Findings so far, however, have been quite disappointing in both respects. Still, the majority of published studies concern either longstanding disease or observational cohorts, and to our knowledge, longitudinal data regarding different ACPA fine specificities in patients with early RA receiving standardised therapy are still lacking. Hence, we set out to analyse the antibody response to immunodominant citrullinated peptides from three candidate autoantigens, in addition to anti-CCP IgG, in the Swedish Farmacotherapy (SWEFOT) trial, a Swedish randomised 2-year clinical trial in early RA, where patients were treated with methotrexate (MTX) for 3 months followed by randomisation of inadequate responders to add-on therapy with either sulfasalazine (SSZ) and hydroxychloroquine (HCQ) or infliximab (IFX). ${ }^{10}$ The aims of the study were (i) to characterise changes in the ACPA response during standardised therapy in early RA, both in terms of levels and occurrence, and (ii) to relate changes in ACPA levels and occurrence to clinical outcomes, such as therapeutic response and radiographic joint damage.

\section{PATIENTS AND METHODS}

\section{Patients}

Serum samples from baseline and 3-month follow-up were available from 316 out of the 487 
patients $(64.9 \%)$ enrolled in the SWEFOT trial, a randomised non-blinded study described in detail elsewhere. ${ }^{10}$ In brief, disease-modifying antirheumatic drug (DMARD)-naive patients with RA with symptom duration $<1$ year were treated with MTX for 3 months, followed by randomisation to add-on therapy with either SSZ and HCQ or IFX in patients with a 28 -joint disease activity score (DAS28) $>3.2$ at the 3-month evaluation. Longitudinally collected serum samples (months $0,3,12$ and 24) were available from 139 out of the 258 (54\%) randomised patients. Baseline characteristics are shown in table 1. Therapeutic response was classified according to the criteria of the European League against Rheumatism (EULAR). ${ }^{11}$ Radiographic progression was determined by the van der Heijde modification of the Sharp score (SHS), as determined on radiographs of hands and feet taken at 0 and 24 months. ${ }^{12}$ All patients gave informed consent.

\section{Laboratory analyses}

Presence and levels of anti-CCP2 antibodies were analysed in serum samples using the second-generation ELISA (Immunoscan CCPlus, EuroDiagnostica AB, Malmö, Sweden) according to the manufacturer's instructions with a cut-off level of 25 arbitrary units $(\mathrm{AU}) / \mathrm{mL}$. Antibodies to citrullinated peptides derived from human $\alpha$-enolase (amino acid (aa) 5-21, CEP-1), vimentin (aa 60-75, cVim) and fibrinogen (aa 36-52, cFib) were analysed using in-house ELISAs as previously described. ${ }^{3}$ Cut-off levels were set according to the 98th centile among 150 non-RA controls and subsequently converted to $10 \mathrm{AU} / \mathrm{mL}$ for all ACPA fine specificities. ${ }^{5}$ Serum samples were stored at $-70^{\circ} \mathrm{C}$ until use, and all samples from each individual were analysed on the same ELISA plate. Any sample that reached the upper limit of the respective ELISA (10\% of anti-CCP tests and 1.0-1.6\% regarding ACPA fine specificities) was further diluted and reanalysed. The dilution at which the optical density plotted close to the centre of the linear part of the standard curve was used to set the new value in terms of $\mathrm{AU} / \mathrm{mL}$. In order to avoid interassay variability, all samples from patients who had $\geq 1$ sample at the upper detection limit were reanalysed.

\section{Statistical analyses}

For each antibody, absolute levels were compared across different time points using Wilcoxon's signed-rank test. To enable comparison between different ACPA specificities, as the units are not identical, relative changes in antibody levels were also calculated. Only patients testing positive at the reference time point, regarding the particular antibody specificity, were included. Differences in patient characteristics, therapeutic responses or radiological progression between patients with serum samples available and those without were analysed by the $\chi^{2}$ test regarding categorical variables and Mann-Whitney $U$ test regarding continuous variables.

Relative changes in antibody levels were then compared according to ACPA specificity, therapeutic response, treatment regimen and radiographic progression by Mann-Whitney U test. Anti-cVim seroreversion was also evaluated using a logistic regression model, where radiographic progression was dichotomised according to SHS increase $>1$ or $>5$, respectively, ${ }^{13}$ adjusted for baseline DAS28, baseline erosions, current smoking status, sex and EULAR response at 3 months. Therapeutic response according to EULAR criteria was dichotomised into responders and non-responders. During add-on therapy, the study protocol allowed switching between therapy groups, and we chose to categorise patients according to the therapy regimen evaluated at the time point of interest, regardless of previous switching.

The proportion of positive ACPA tests over time was analysed by McNemar's test and across ACPA specificities by Fisher's exact test. Changes in erythrocyte sedimentation rate (ESR), C-reactive protein (CRP) level and DAS28 among EULAR nonresponders were evaluated with paired $t$ test. Non-parametric correlations were performed to evaluate the relation between changes in antibody levels, ESR/CRP and radiographic progression, respectively. The relationship between the numbers of ACPAs present at baseline and DAS28 were tested by one-way analysis of variance (ANOVA) with Bonferroni post hoc tests and ANOVA for repeated measurements. Two-sided $\mathrm{p}$ values $<0.05$ were considered significant throughout. The statistical analyses were performed using SPSS for Windows V.20.

\section{RESULTS \\ Descriptive characterisation of the ACPA response during early RA}

Patient characteristics are shown in table 1 . We found no significant differences between patients with serum samples available, compared with those without, regarding the clinical characteristics shown in table 1, EULAR response rates at months 3 and 12 or median 2-year difference in SHS ( $p>0.05$ for all). Changes in ACPA levels during follow-up, in baseline antibodypositive patients subsequently receiving add-on treatment, are shown in figure 1. Absolute levels of all tested ACPAs declined both during months $0-3$ ( $\mathrm{p}<0.001$ for all specificities) and months $3-12(\mathrm{p}<0.001$ regarding anti-CCP, $\mathrm{p}<0.01$ regarding anti-CEP-1, anti-cVim and anti-cFib antibodies), while no significant change could be detected for any ACPA during months 12-24. As shown in figure 2, the proportion of patients testing positive declined significantly between 0 and 24 months regarding anti-CEP-1 (40.9\% vs $28.2 \%, \mathrm{p}=0.002)$, anti-cVim $(31.2 \%$ vs $13.0 \%, \mathrm{p}<0.001)$ and anti-cFib antibodies $(29.7 \%$ vs $22.2 \%$, $\mathrm{p}=0.019)$, whereas anti-CCP antibody status remained unaltered $(69.8 \%$ vs $67.6 \%$ positive, $\mathrm{p}=0.45)$. Reversion from positive at baseline to negative at 2 years was significantly more common regarding anti-cVim (26 out of 43) compared with anti-CEP-1 ( 20 out of $54, p=0.026)$, anti-cFib (15 out of $41, p=0.032)$ and anti-CCP antibodies (5 out of $97, \mathrm{p}<0.0001$ ), respectively. Among patients testing negative at baseline, one (1\%) had turned positive at the 24-month follow-up regarding anti-cVim antibodies, four (5\%) regarding anti-CEP-1, five (4\%) regarding anti-cFib and three $(5 \%)$ regarding anti-CCP antibodies.

Relative changes in ACPA levels in baseline antibody-positive patients subsequently receiving add-on treatment are detailed in online supplementary table S1. There were no statistically significant differences in relative changes between ACPA specificities during any follow-up period.

\section{ACPA response in relation to therapeutic response}

The relative changes in different ACPAs in relation to MTX response are depicted in figure 3A. Median antibody declines were non-significantly greater in EULAR responders compared with EULAR non-responders regarding all ACPA specificities. During add-on therapy, that is, months 3-12, levels of all ACPAs showed greater declines among responders compared with non-responders, reaching statistical significance for anti-cVim $(\mathrm{p}=0.034)$ and anti-CCP $\operatorname{IgG}(\mathrm{p}=0.025)$, and borderline significance for anti-CEP-1 $\operatorname{IgG}(p=0.075)$ (figure $3 \mathrm{~B})$. We also tested whether relative changes in ACPA levels correlated to changes in DAS28 or inflammatory markers (detailed in online supplementary table S1). 
Table 1 Patient characteristics according to treatment modality

\begin{tabular}{|c|c|c|c|}
\hline & $\begin{array}{l}\text { Initial MTX monotherapy } \\
\text { (months } 0-3, n=316 \text { ) }\end{array}$ & $\begin{array}{l}\text { Add-on DMARD combination } \\
\text { (months } 3-12, n=55 \text { ) }\end{array}$ & $\begin{array}{l}\text { Add-on TNF inhibitor } \\
\text { (months 3-12, } \mathrm{n}=84 \text { ) }\end{array}$ \\
\hline Women (\%) & $231(73)$ & $45(82)$ & $64(76)$ \\
\hline Disease duration, mean months (SD) & $6.2(4.8)$ & $5.8(3.0)$ & $6.2(3.4)$ \\
\hline Rheumatoid factor positive (\%) & $213(67)$ & $37(67)$ & $53(63)$ \\
\hline Concurrent low-dose prednisolone (\%) & $42(13)$ & $6(11)$ & $8(10)$ \\
\hline DAS28, mean (SD) & $5.7(1.0)$ & $5.9(1.0)$ & $6.0(1.0)$ \\
\hline DAS28 at 3 months, mean (SD) & $4.0(1.4)$ & $4.7(1.0)$ & $5.0(1.0)$ \\
\hline Erosions, $\mathrm{n}(\%)^{*}$ & $107(38)$ & $22(45)$ & $27(36)$ \\
\hline Median anti-CCP level, AU/mL (IQR)† & $811(259-2147)$ & $874(234-2556)$ & $743(187-1883)$ \\
\hline Median anti-CEP-1 level, U/mL (IQR)† & $50.7(21.3-119.5)$ & $45.8(20.8-113.7)$ & $46.0(20.4-103.4)$ \\
\hline Median anti-cVim level, U/mL (IQR)† & $22.7(14.4-40.8)$ & $25.3(11.2-31.6)$ & $20.4(14.6-38.3)$ \\
\hline Median anti-cFib level, U/mL (IQR) $\dagger$ & $32.6(18.6-64.1)$ & $40.7(18.2-64.1)$ & $23.3(15.3-46.8)$ \\
\hline Median number of ACPAs, median (range) & $2(0-4)$ & $2(0-4)$ & $1(0-4)$ \\
\hline
\end{tabular}

As non-responders to add-on triple therapy or tumour necrosis factor (TNF) inhibitor demonstrated less pronounced ACPA declines than non-responders to initial MTX monotherapy (figure 3A, B), we wanted to test whether small improvements had occurred although EULAR response criteria were not met. Indeed, there were small but statistically significant improvements among non-responders to initial MTX monotherapy regarding ESR (mean difference $-7 \mathrm{~mm} / \mathrm{h}, \mathrm{p}=0.001$ ), CRP $(-9 \mathrm{mg} / \mathrm{L}, \mathrm{p}=0.001)$ and DAS28 $(-0.2, \mathrm{p}=0.001)$, whereas no significant differences were found regarding non-responders to add-on therapy ( $p>0.2$ for all).

Next, we related changes in antibody levels during months 312 to add-on treatment modality within the same time period. No significant differences were found between patients receiving add-on DMARDs compared with those that received IFX (figure 4). Likewise, using a dichotomous definition (positive/ negative), neither the 0-month and 3-month ACPA status nor ACPA reversion associated with EULAR response at 3 or

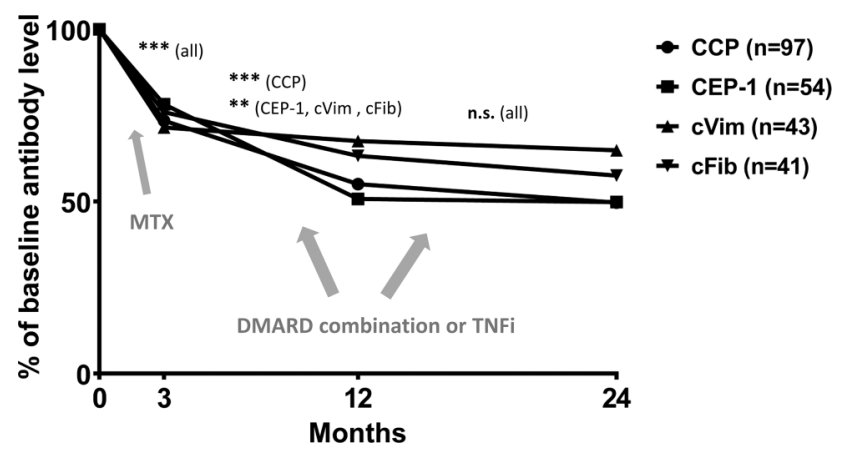

Figure 1 Relative change in levels of different anticitrullinated protein antibody (ACPA) specificities in patients with early rheumatoid arthritis receiving add-on therapy at 3 months. For each ACPA specificity, only patients testing positive at baseline were included. ${ }^{* *} p<0.001$, ${ }^{* *} p<0.01$, n.s., not significant, as tested by non-parametric statistics on absolute antibody levels. CCP, cyclic citrullinated peptide; CEP-1, citrullinated $\alpha$-enolase peptide-1; cVim, citrullinated vimentin peptide; cFib, citrullinated fibrinogen peptide; MTX, methotrexate; DMARD, disease-modifying anti-rheumatic drugs; TNFi, tumour necrosis factor inhibitor.
12 months (data not shown). In these analyses, patients who switched treatment group (12 patients positive for anti-CCP, 6 for anti-CEP-1, 4 for anti-cVim and 3 for anti-cFib antibodies) were categorised according to the therapy evaluated at the 12-month visit, and importantly the change in ACPA levels was very similar among patients who switched (all but one switched from DMARD combination to IFX) compared with patients treated with the same drug throughout the whole 9-month period (data not shown).

Finally, the number of ACPA specificities present at baseline was related to EULAR responses and DAS28 over time. There was a statistically significant difference in baseline DAS28 according to the number of ACPAs present $(p=0.035)$, where post hoc tests showed that patients testing positive for two ACPAs tended to have lower DAS28 compared with those with

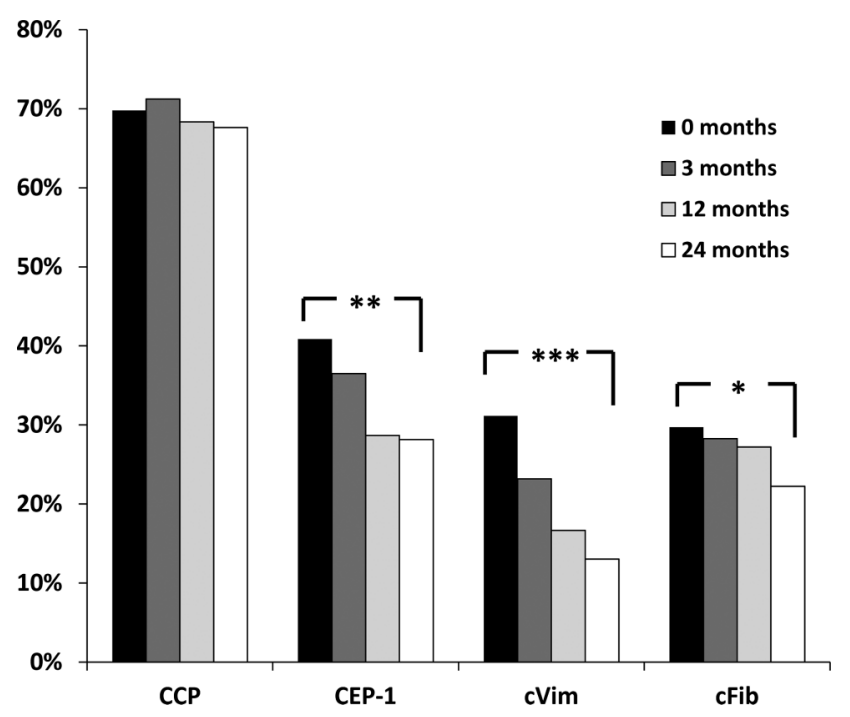

Figure 2 Status of different anticitrullinated protein antibody specificities at different time points in early rheumatoid arthritis. Only patients receiving add-on therapy were included $(n=139)$. * $p=0.019$, ${ }^{* *} \mathrm{p}=0.002,{ }^{* *} \mathrm{p}<0.001$, comparing $0-24$ months. CCP, cyclic citrullinated peptide; CEP-1, citrullinated $\alpha$-enolase peptide-1; $c$ Vim, citrullinated vimentin peptide; cFib, citrullinated fibrinogen peptide. 


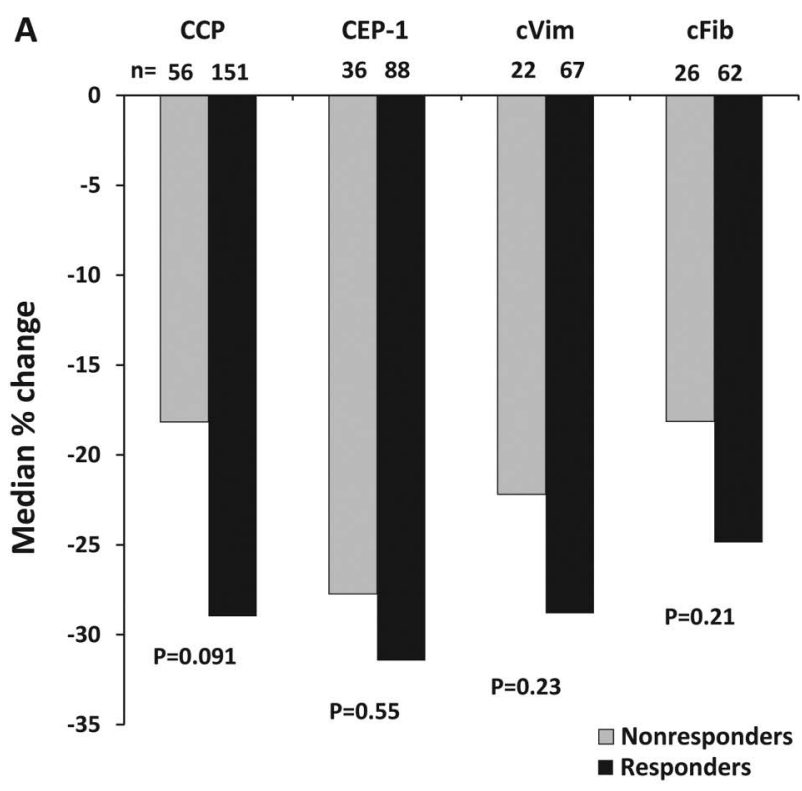

B

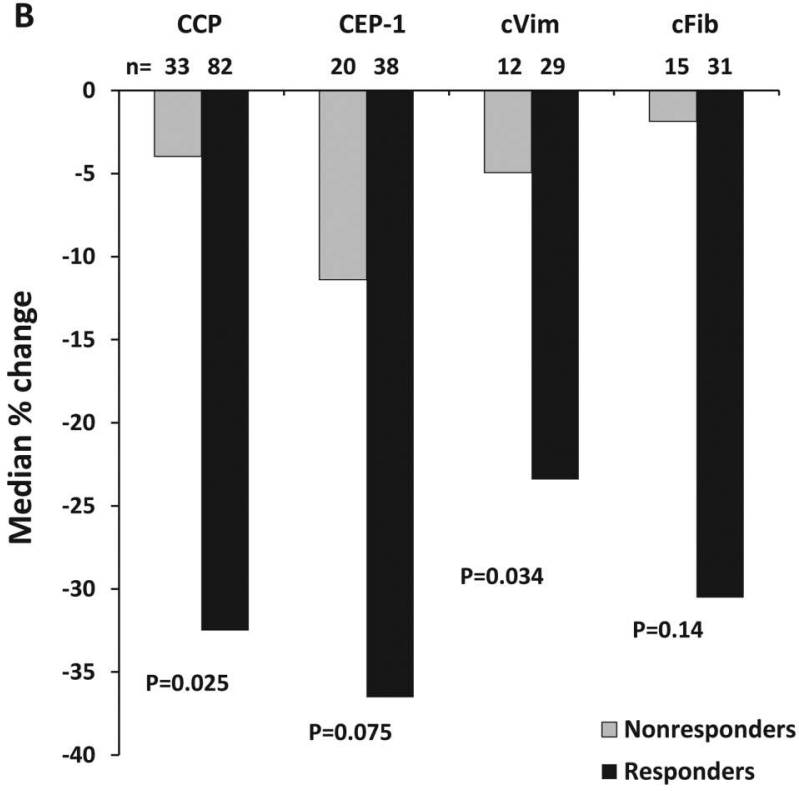

Figure 3 Relative changes in antibody levels in relation to treatment response after 3 months of methotrexate therapy (A) and after 9 months of add-on therapy (B) in early rheumatoid arthritis. CCP, cyclic citrullinated peptide; CEP-1, citrullinated $\alpha$-enolase peptide-1; cVim, citrullinated vimentin peptide; cFib, citrullinated fibrinogen peptide.

four ACPAs $(p=0.068)$ and compared with those without any of the tested ACPAs $(p=0.067)$. ANOVA for repeated measurements showed no significant impact of the number of ACPAs on DAS28 during follow-up ( $\mathrm{p}=0.82$; see online supplementary figure S1). The number of ACPAs present at baseline was not related to EULAR responses at 3 or 12 months (data not shown).

\section{ACPA response in relation to radiographic progression}

Change in antibody status within the first three months was related to radiographic progression during 2 years (table 2). Reversion from positive to negative regarding anti-cVim antibody status was associated with lower total SHS at 2 years

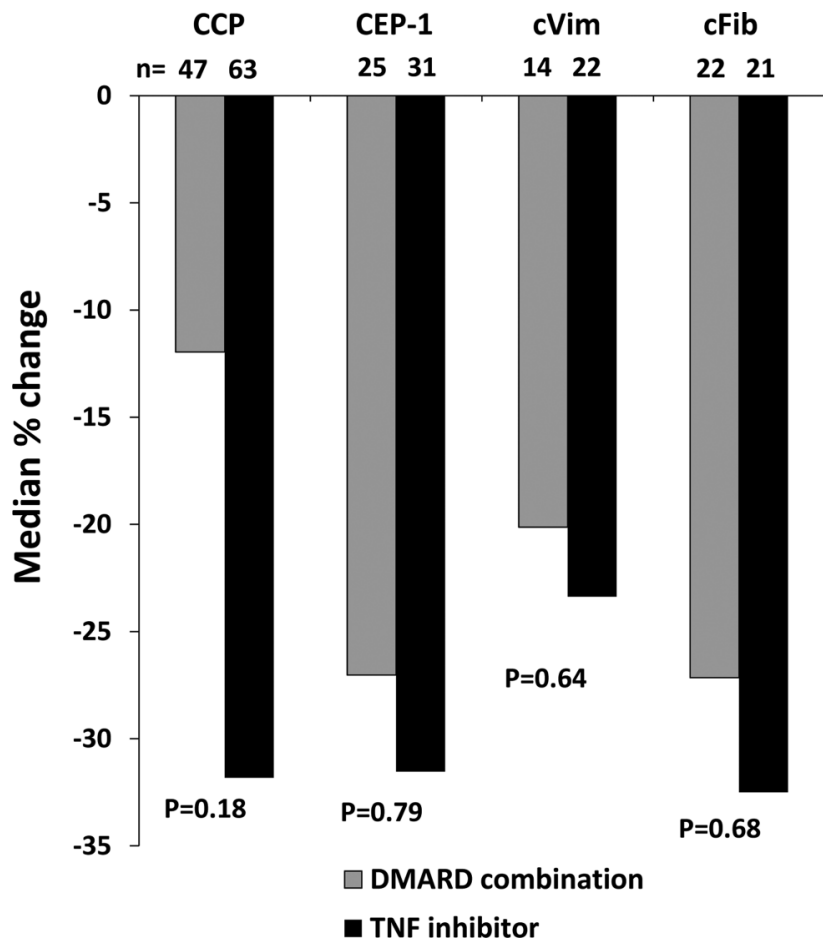

Figure 4 Relative changes in antibody levels during months 3-12 in relation to add-on therapy regimen following inadequate response to methotrexate in early rheumatoid arthritis. CCP, cyclic citrullinated peptide; CEP-1, citrullinated $\alpha$-enolase peptide-1; cVim, citrullinated vimentin peptide; $c$ Fib, citrullinated fibrinogen peptide; DMARD, disease-modifying anti-rheumatic drugs; TNF, tumour necrosis factor.

and a lower rate of radiographic progression compared with those who remained positive $(p=0.012$ and 0.015 , respectively), while no significant differences were found regarding anti-cFib and anti-CEP-1 antibody seroreversions (table 2). Anti-cVim antibody seroreversion remained associated with less occurrence of radiological progression after adjusting for baseline DAS28, baseline erosions, current smoking status, sex and EULAR response at 3 months $(p=0.005$ for SHS progression $>1$ and $\mathrm{p}=0.013$ for SHS progression $>5$, respectively).

We also tested whether the number of ACPAs present at baseline was related to radiographic progression. Median SHS progression differed significantly according to number of ACPAs present $(p=0.010)$, but not when analysing patients with $\geq 1$ ACPA only. As anti-CCP IgG was present in $98 \%$ of the patients with $\geq 1$ ACPA, we expected anti-CCP antibodies to be the strongest baseline predictor of radiographic progression. Indeed, patients with anti-CCP antibodies at baseline had a larger median 2-year increase in SHS $(\mathrm{p}=0.001)$ than anti-CCP antibody-negative patients. This was also seen regarding antibodies to $c F i b(p=0.022)$, while the differences did not reach statistical significance regarding anti-CEP-1 and anti-cVim antibodies ( $p=0.079$ and 0.13 , respectively). In a multivariate model including all ACPAs and the adjustments described above, only anti-CCP antibody occurrence remained significantly associated with SHS progression $>1(p=0.024)$, while the ACPA fine specificities did not $(p>0.28$ for all). The latter was not altered by removing anti-CCP antibody status from the model. No significant correlations were found between relative changes in ACPA levels of any specificity and the 2-year SHS, or 2-year radiographic progression (data not shown). 
Table 2 Change in ACPA status during the initial three months in relation to radiographic outcome during 2 years

\begin{tabular}{|c|c|c|c|c|c|c|c|c|c|c|c|c|}
\hline \multirow[b]{2}{*}{$\begin{array}{l}0-13 \text {-months } \\
\text { antibody status }\end{array}$} & \multicolumn{4}{|c|}{ Anti-cVim } & \multicolumn{4}{|c|}{ Anti-CEP-1 } & \multicolumn{4}{|l|}{ Anti-cFib } \\
\hline & $\begin{array}{l}-l- \\
(n=178)\end{array}$ & $\begin{array}{l}+/- \\
(n=21)\end{array}$ & $\begin{array}{l}+/+ \\
(n=54)\end{array}$ & p Value* & $\begin{array}{l}-l- \\
(n=153)\end{array}$ & $\begin{array}{l}+/- \\
(n=14)\end{array}$ & $\begin{array}{l}+/+ \\
(n=85)\end{array}$ & $\begin{array}{l}p \\
\text { Value* }\end{array}$ & $\begin{array}{l}-l- \\
(\mathrm{n}=179)\end{array}$ & $\begin{array}{l}+/- \\
(n=12)\end{array}$ & $\begin{array}{l}+/+ \\
(n=60)\end{array}$ & p Value* \\
\hline $\begin{array}{l}\text { SHS total score at } \\
\text { baseline }\end{array}$ & $1(0-6)$ & $1(0-4.5)$ & $2(0-5)$ & 0.66 & $1(0-5)$ & $2.5(0-6)$ & $2(0-6.5)$ & 0.73 & $1(0-5)$ & $4(0-7.5)$ & $3(0-6)$ & 0.81 \\
\hline $\begin{array}{l}\text { SHS total score at } \\
2 \text { years }\end{array}$ & $4(0-12)$ & $0(0-10.5)$ & $7(3.8-13.3)$ & 0.012 & $4(0-10)$ & $5(0-13.5)$ & $9(3-16)$ & 0.33 & $4(0-10)$ & $9(4-21)$ & $9.5(2-13.8)$ & 0.72 \\
\hline $\begin{array}{l}\text { Change in total } \\
\text { score during } 2 \text { years }\end{array}$ & $1(0-6)$ & $0(0-4)$ & $4(0-10.3)$ & 0.015 & $1(0-5)$ & $1.5(0-7)$ & $4(0-11.5)$ & 0.65 & $1(0-5)$ & $5(0-13.3)$ & $3.5(0-9)$ & 0.59 \\
\hline
\end{tabular}

\section{DISCUSSION}

In this longitudinal investigation of multiple ACPA specificities in early RA, we found substantial heterogeneity in how different ACPAs disappear from the circulation upon antirheumatic therapy. In contrast to anti-CCP IgG, all tested ACPA fine specificities showed declining occurrence over time. Anti-cVim antibodies were the most common to revert from positive to negative, and their early disappearance associated with less radiological progression. Thus, the current study suggests that the disappearance of particular ACPA reactivities may be beneficial in early RA.

With regards to changes in ACPA levels, we found that levels of all ACPAs declined independent of therapeutic response during the first three months of MTX treatment. Whether this phenomenon is specific for MTX monotherapy, or a result of initial antirheumatic therapy per se, or even a consequence of the longitudinal course of disease, cannot be determined as no control group to MTX monotherapy was included. In line with our data, Mikuls et $a l^{14}$ found that anti-CCP antibody reduction was associated with early disease, but not with therapeutic response to oral DMARDs. Also, Rönnelid et $a l^{15}$ reported significant anti-CCP antibody declines during the first year of early RA, without association to therapeutic response to oral DMARDs. In contrast, Böhler et al $^{16}$ described response-associated ACPA declines in an RA cohort with mean disease duration of $>5$ years, but found no relation to disease duration. In a Canadian early arthritis cohort, anti-CCP antibody fluctuations did not relate to clinical outcome. ${ }^{17}$ Differences in study populations and follow-up strategies might underlie these somewhat discrepant results.

Our finding that anti-cVim antibodies were the most frequent ACPA specificity to disappear from the circulation is in line with previously published data concerning the related anti-Sa antibody in a North American early polyarthritis cohort. ${ }^{18}$ In contrast, two smaller studies found stable occurrence of autoantibodies to vimentin-derived citrullinated antigens over 3 and 7 years of early RA, respectively. ${ }^{19}{ }^{20}$ Rantapää-Dahlqvist and coworkers found declining levels of antibodies to mutated citrullinated vimentin (MCV) in patients with early RA who responded to therapy, ${ }^{21}$ while Guzian et $a l^{18}$ reported an equally severe disease course in patients with polyarthritis turning negative for anti-Sa antibodies compared with those remaining positive. With regards to prediction of radiological outcome, baseline testing for different ACPA specificities has previously shown little value if the anti-CCP antibody status was known. ${ }^{22-24}$ However, there are a number of reports suggesting a more pronounced association between antibodies to vimentinderived citrullinated antigens and radiological progression. ${ }^{25-27}$
In addition, anti-MCV antibodies were recently shown to directly mediate bone resorption. ${ }^{28}$ Against this background, it is intriguing to see that our study clearly demonstrates an association between the early disappearance of specific anti-cVim antibodies and less radiological progression, also after adjustments for other known predictors such as baseline joint damage and current smoking. ${ }^{13}$

Interestingly, we observed a trend towards greater decline in ACPA levels among responders to add-on therapy compared with non-responders, regardless of whether therapeutic response was achieved by DMARD combination therapy or addition of a TNF inhibitor. We have no apparent explanation as to why non-responders demonstrate declining ACPA levels during the first three months of MTX monotherapy, but not during non-response to add-on triple therapy or TNF inhibitor. One very speculative explanation to the disparate response associations between therapy regimens (and time points) could be that there are qualitative differences in ACPAs affected by the initial therapy, compared with ACPAs declining later, or in response to intensified therapy. Such qualitative differences could include, for instance, antibody isotype/subclass, glycosylation pattern or avidity, ${ }^{29}{ }^{30}$ which in turn may influence the pathogenic potential of the autoantibodies. The fact that non-responders to MTX, in contrast to add-on therapy non-responders, experienced slight improvements in ESR, CRP and DAS28 may have also influenced these findings.

We found that the propensity of the different ACPAs to revert from positive to negative was anti-cVim $>$ anti-CEP- $1=$ anticFib $>$ anti-CCP despite similar relative changes in antibody levels. Thus, one could argue that differences in cut-off procedures underlie these findings, but the in-house citrullinated peptide ELISA assays used for detecting anti-cVim, anti-cFib and anti-CEP-1 antibodies have the same reference sample and cut-off limit (98th centile among 150 non-RA controls). Moreover, since the commercial anti-CCP ELISA kit uses an even more stringent cut-off, corresponding to the 99th centile among 260 blood donors and the 98th centile among 521 disease controls, this actually strengthens the differences observed between anti-CCP antibodies and the ACPA fine specificities. Thus, anti-CCP antibodies likely act as surrogate markers not only for antibodies against CEP-1, cVim and cFib but also for ACPAs targeting other citrullinated antigens, not investigated here, and that may remain unaltered during pharmacotherapy. At the same time, one cannot rule out the possibility that other ACPA specificities, not investigated by us, would demonstrate even more decrease and seroreversion, in response to therapy, than we could observe for anti-cVim antibodies. 
A weakness of the current study is that a substantial proportion of patients did not have serum samples available from all follow-up visits. There are, however, no differences in clinical characteristics, response patterns or radiological progression between those who had available serum samples and those who had not. Therefore, we believe that this fact is unlikely to have a major influence on the results.

We conclude that the effect of early antirheumatic therapy on circulating ACPAs is markedly different across different antibody specificities with regards to seroreversion. The association between the disappearance of anti-cVim antibodies after 3 months and less radiological progression at 24 months should encourage further work to explore the prognostic potential of repeated measurements of different ACPA specificities in early RA.

\section{Acknowledgements We wish to thank Lena Israelsson for expert technical assistance, and all the participating clinicians, nurses and patients who made the original SWEFOT trial possible.}

Contributors All authors made substantial contributions to conception and design, or interpretation of data, drafting the article or revising it critically for important intellectual content and final approval of the version to be published.

Funding This study was financed by grants from the EU-funded FP7 projects Gums \& Joints (FP7-Health-2010-261460) and TRIGGER (FP7-Health-2013-306029), the County Council of Östergötland, the Reinhold Sund Foundation, the Swedish Society of Medicine, the Swedish Rheumatism Association, the Thelma Zoégas foundation in Helsingborg and "Stiftelsen för Rörelsehindrade i Skåne", as well as the Swedish Research Council and the Strategic Foundations of Sweden (SSF).

Competing interests IFP participates in speaker's bureau for UCB Pharma, AbbVie and Pfizer. RvV has received grants/research support from AbbVie, BMS, GSK, Pfizer, Roche and UCB Pharma, and consultancy/honoraria from AbbVie, Biotest, BMS, GSK, Janssen, Lilly, Merck, Pfizer, Roche, UCB and Vertex. LK had received research grants from AbbVie, BMS, Pfizer, Roche, UCB Pharma, NovoNordisk, Janssen and Sobi. KL is co-inventor of patent US12/524,465, describing the diagnostic use of the CEP-1 epitope. All other authors declare no potentially competing interests.

Ethics approval The regional ethics committees of the participating Swedish hospitals.

Provenance and peer review Not commissioned; externally peer reviewed.

Open Access This is an Open Access article distributed in accordance with the Creative Commons Attribution Non Commercial (CC BY-NC 4.0) license, which permits others to distribute, remix, adapt, build upon this work non-commercially, and license their derivative works on different terms, provided the original work is properly cited and the use is non-commercial. See: http://creativecommons.org/ licenses/by-nc/4.0/

\section{REFERENCES}

1 Willemze A, Trouw LA, Toes REM, et al. The influence of ACPA status and characteristics on the course of RA. Nat Rev Rheumatol 2012;8:144-52.

2 Wegner $\mathrm{N}$, Lundberg $\mathrm{K}$, Kinloch $\mathrm{A}$, et al. Autoimmunity to specific citrullinated proteins gives the first clues to the etiology of rheumatoid arthritis. Immunol Rev 2010:233:34-54.

3 Snir $\mathrm{O}$, Widhe $\mathrm{M}$, von Spee $\mathrm{C}$, et al. Multiple antibody reactivities to citrullinated antigens in sera from patients with rheumatoid arthritis: association with HLA-DRB1 alleles. Ann Rheum Dis 2009;68:736-43.

4 Goules JD, Goules AV, Tzioufas AG. Fine specificity of anti-citrullinated peptide antibodies discloses a heterogeneous antibody population in rheumatoid arthritis. Clin Exp Immunol 2013;174:10-7.

5 Lundberg K, Bengtsson C, Kharlamova N, et al. Genetic and environmental determinants for disease risk in subsets of rheumatoid arthritis defined by the anticitrullinated protein/peptide antibody fine specificity profile. Ann Rheum Dis 2013;72:652-58.

6 Scherer HU, van der Woude D, Willemze A, et al. Distinct ACPA fine specificities, formed under the influence of HLA shared epitope alleles, have no effect on radiographic joint damage in rheumatoid arthritis. Ann Rheum Dis 2011;70:1461-4.

7 Brink M, Hansson M, Mathsson L, et al. Multiplex analyses of antibodies against citrullinated peptides in individuals prior to development of rheumatoid arthritis. Arthritis Rheum 2013:65:899-910.

8 Sokolove J, Bromberg R, Deane KD, et al. Autoantibody epitope spreading in the pre-clinical phase predicts progression to rheumatoid arthritis. PLOS ONE 2012;7:e35296.
9 Modi S, Soejima M, Levesque MC. The effect of targeted rheumatoid arthritis therapies on anti-citrullinated protein autoantibody levels and B cell responses. Clin Exp Immunol 2013;173:8-17.

10 van Vollenhoven RF, Geborek P, Forslind K, et al. Conventional combination treatment versus biological treatment in methotrexate-refractory early rheumatoid arthritis: 2 year follow-up of the randomised, non-blinded, parallel-group Swefot trial. Lancet 2012;379:1712-20.

11 van Gestel AM, Prevoo ML, van 't Hof MA, et al. Development and validation of the European League Against Rheumatism response criteria for rheumatoid arthritis. Comparison with the preliminary American College of Rheumatology and the World Health Organization/International League Against Rheumatism Criteria. Arthritis Rheum 1996:39:34-40.

12 van der Heijde D. How to read radiographs according to the Sharp/van der Heijde method. J Rheumatol 2000;27:261-3.

13 Saevarsdottir S, Rezaei H, Geborek P, et al. Current smoking status is a strong predictor of radiographic progression in early rheumatoid arthritis: results from the SWEFOT trial. Ann Rheum Dis 2015:74:1509-14.

14 Mikuls TR, O'Dell JR, Stoner JA, et al. Association of rheumatoid arthritis treatment response and disease duration with declines in serum levels of IgM rheumatoid factor and anti-cyclic citrullinated peptide antibody. Arthritis Rheum 2004:50:3776-82.

15 Rönnelid J, Wick MC, Lampa J, et al. Longitudinal analysis of citrullinated protein/ peptide antibodies (anti-CP) during 5 year follow up in early rheumatoid arthritis: anti-CP status predicts worse disease activity and greater radiological progression. Ann Rheum Dis 2005;64:1744-9.

16 Böhler C, Radner H, Smolen JS, et al. Serological changes in the course of traditional and biological disease modifying therapy of rheumatoid arthritis. Ann Rheum Dis 2013:72:241-44.

17 Barra L, Bykerk V, Pope JE, et al. Anticitrullinated protein antibodies and rheumatoid factor fluctuate in early inflammatory arthritis and do not predict clinical outcomes. J Rheumatol 2013;40:1259-67.

18 Guzian M-C, Carrier N, Cossette P, et al. Outcomes in recent-onset inflammatory polyarthritis differ according to initial titers, persistence over time, and specificity of the autoantibodies. Arthritis Care Res 2010;62:1624-32.

19 da Mota LM, Santos Neto LL, Pereira IA, et al. Autoantibodies in early rheumatoid arthritis: Brasília cohort-results of a three-year serial analysis. Rev Bras Reumatol 2011:51:564-71.

20 van der Woude D, Rantapää-Dahlqvist S, loan-Facsinay A, et al. Epitope spreading of the anti-citrullinated protein antibody response occurs before disease onset and is associated with the disease course of early arthritis. Ann Rheum Dis 2010;69:1554-61.

21 Innala L, Kokkonen $\mathrm{H}$, Eriksson C, et al. Antibodies against mutated citrullinated vimentin are a better predictor of disease activity at 24 months in early rheumatoid arthritis than antibodies against cyclic citrullinated peptides. I Rheumatol 2008; $35: 1002-8$

22 Fisher BA, Plant D, Brode M, et al. Antibodies to citrullinated alpha-enolase peptide 1 and clinical and radiological outcomes in rheumatoid arthritis. Ann Rheum Dis 2011;70:1095-8.

23 van Beers JJ, Willemze A, Jansen JJ, et al. ACPA fine-specificity profiles in early rheumatoid arthritis patients do not correlate with clinical features at baseline or with disease progression. Arthritis Res Ther 2013;15:R140.

24 Willemze A, Bohringer $S$, Knevel R, et al. The ACPA recognition profile and subgrouping of ACPA-positive RA patients. Ann Rheum Dis 2012; 71:268-74.

25 Carrier N, Cossette P, Daniel C, et al. The DERAA HLA-DR alleles in patients with early polyarthritis: protection against severe disease and lack of association with rheumatoid arthritis autoantibodies. Arthritis \& Rheumatism 2009;60:698-707.

26 Mathsson L, Mullazehi M, Wick MC, et al. Antibodies against citrullinated vimentin in rheumatoid arthritis: higher sensitivity and extended prognostic value concerning future radiographic progression as compared with antibodies against cyclic citrullinated peptides. Arthritis Rheum 2008;58:36-45.

27 Syversen SW, Goll GL, van der Heijde D, et al. Prediction of radiographic progression in rheumatoid arthritis and the role of antibodies against mutated citrullinated vimentin: results from a 10-year prospective study. Ann Rheum Dis 2010;69:345-1.

28 Harre $\mathrm{U}$, Georgess $\mathrm{D}$, Bang $\mathrm{H}$, et al. Induction of osteoclastogenesis and bone loss by human autoantibodies against citrullinated vimentin. J Clin Invest 2012;122:1791-802.

29 Scherer HU, van der Woude D, loan-Facsinay A, et al. Glycan profiling of anti-citrullinated protein antibodies isolated from human serum and synovial fluid. Arthritis Rheum 2010;62:1620-9.

30 Suwannalai $P$, van de Stadt $L A$, Radner $H$, et al. Avidity maturation of anticitrullinated protein antibodies in rheumatoid arthritis. Arthritis \& Rheumatism 2012:64:1323-8. 